University of Nebraska - Lincoln

DigitalCommons@University of Nebraska - Lincoln

July 1996

\title{
Nickel doping of boron carbide grown by plasma enhanced chemical vapor deposition
}

\author{
Seong-Don Hwang \\ University of Nebraska-Lincoln \\ N.B. Remmes \\ University of Nebraska-Lincoln \\ Peter A. Dowben \\ University of Nebraska-Lincoln, pdowben@unl.edu \\ D.N. Mcllroy \\ University of Idaho
}

Follow this and additional works at: https://digitalcommons.unl.edu/physicsdowben

Part of the Physics Commons

Hwang, Seong-Don; Remmes, N.B.; Dowben, Peter A.; and Mcllroy, D.N., "Nickel doping of boron carbide grown by plasma enhanced chemical vapor deposition" (1996). Peter Dowben Publications. 146.

https://digitalcommons.unl.edu/physicsdowben/146

This Article is brought to you for free and open access by the Research Papers in Physics and Astronomy at DigitalCommons@University of Nebraska - Lincoln. It has been accepted for inclusion in Peter Dowben Publications by an authorized administrator of DigitalCommons@University of Nebraska - Lincoln. 


\title{
Nickel doping of boron carbide grown by plasma enhanced chemical vapor deposition
}

\author{
Seong-Don Hwang, N. B. Remmes, and P. A. Dowben ${ }^{\text {a) }}$ \\ Center for Materials Research and Analysis, Department of Physics, Behlen Laboratory of Physics, \\ University of Nebraska, Lincoln, Nebraska 68588-0111 \\ D. N. Mcllroy \\ Department of Physics, University of Idaho, Moscow, Idaho 83844-0903
}

(Received 22 January 1996; accepted 15 March 1996)

\begin{abstract}
We have nickel doped boron carbide grown by plasma enhanced chemical vapor deposition. The source gas closo-1,2-dicarbadodecaborane (ortho-carborane) was used to grow the boron carbide, while nickelocene $\left[\mathrm{Ni}\left(\mathrm{C}_{5} \mathrm{H}_{5}\right)_{2}\right]$ was used to introduce nickel into the growing film. The doping of nickel transformed a $p$-type, $\mathrm{B}_{5} \mathrm{C}$ material, relative to lightly doped $n$-type silicon, to an $n$-type material. Both $n$ - $n$ heterojunction diodes and $n$ - $p$ heterojunction diodes were constructed, using as substrates $n$ - and $p$-type $\mathrm{Si}(111)$, respectively. With sufficient partial pressures of nickelocene in the plasma reactor, diodes with characteristic tunnel diode behavior can be successfully fabricated.
\end{abstract}

(C) 1996 American Vacuum Society.

\section{INTRODUCTION}

Through the decomposition of cluster borane molecules by plasma-enhanced ${ }^{1-4}$ and synchrotron radiation-induced ${ }^{4,5}$ chemical vapor deposition, heterojunction devices of boron and boron carbide have been successfully fabricated. These techniques have not only been used to construct simple diodes, but have also successfully yielded field effect transistors. ${ }^{3}$ Until now, no attempts have been made to intentionally dope the intrinsic films of boron carbide using the technique of plasma enhanced chemical vapor deposition (PECVD).

The introduction of metal dopants into boron carbide is not a trivial process. Initial attempts to dope molecular films of the precursor cluster molecule closo-1,2dicarbadodecaborane $\left(\mathrm{C}_{2} \mathrm{~B}_{10} \mathrm{H}_{12}\right)$, otherwise known as orthocarborane, with the common dopant mercury were unsuccessful. ${ }^{6}$ Mercury was found to segregate to the molecular film-substrate interface and is indicative of the weak interaction between $\mathrm{Hg}$ and orthocarborane. While initially disappointing, subsequent attempts to dope molecular films of orthocarborane did prove to be successful. ${ }^{6,7}$ Such molecular films can be doped with sodium. ${ }^{6,7}$ The possibility of doping boron carbide with $\mathrm{Hg}$ cannot be excluded based on these results. This work, nonetheless, did suggest that doping of this material may be a complex process. This is particularly true since the suitability of orthocarborane $\left(\mathrm{C}_{2} \mathrm{~B}_{10} \mathrm{H}_{12}\right)$ for the chemical vapor deposition of a $\mathrm{B}_{5} \mathrm{C}$ films has been established $^{3-5}$ and because this molecule is very similar to the "building block" of boron carbide.

Nickel, however, is a very promising dopant for the boron rich solids. A molecular nickel carborane complex has been synthesized by inorganic chemists ${ }^{8}$ and the inclusion of nickel in other boron rich solids is well established. Nickel is a common component in the boron carbide superconductors 9 and the reactions of nickel with boron phosphide have been

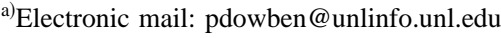

investigated. ${ }^{10-11}$ Nickelocene, $\mathrm{Ni}\left(\mathrm{C}_{5} \mathrm{H}_{5}\right)_{2}$, has been shown to be a suitable source compound for the deposition of nickel containing thin films. ${ }^{12}$ Nickelocene is volatile and far less toxic than nickel-tetracarbonyl, though a number of other nickel containing organometallic compounds may be suitable. ${ }^{13}$ Since both orthocarborane and nickelocene are easily sublimed from the solid, introduction of suitable mixtures into the plasma reactor can be readily accomplished. In this paper we present the device characteristics of diodes constructed with nickel doped boron carbide grown by PECVD. To the best of our knowledge, this is the first successful demonstration of metal doping of boron carbide films grown by PECVD. Both high and low levels of Ni doping of boron carbide have been investigated. The diode devices have markedly different behaviors depending upon the nickel doping.

\section{EXPERIMENT}

The $p-n$ and $n-p$ heterojunctions were formed by depositing boron carbide thin films on $n$-type and $p$-type $\mathrm{Si}(111)$ substrates, respectively, following procedures described in detail elsewhere. ${ }^{1,2}$ Deposition of films was performed in a custom designed parallel plate $13.56 \mathrm{MHz}$ radio-frequency PECVD reactor used in previous studies. ${ }^{1,2}$ The silicon substrates were doped to $7 \times 10^{14} / \mathrm{cm}^{3}$. The $\mathrm{Si}(111)$ substrates surfaces were prepared by $\mathrm{Ar}^{+}$ion sputtering in the plasma reactor. The source molecule gas closo-1,2dicarbadodecaborane (ortho-carborane) was used as the source compound for growing the boron carbide, while nickelocene $\left[\mathrm{Ni}\left(\mathrm{C}_{5} \mathrm{H}_{5}\right)_{2}\right]$ was used to introduce nickel into the growing film. As discussed above, nickelocene $\left[\mathrm{Ni}\left(\mathrm{C}_{5} \mathrm{H}_{5}\right)_{2}\right]$ was simultaneously introduced into the plasma reactor with orthocarborane [closo-1,2-dicarbadodecaborane $\left(\mathrm{C}_{2} \mathrm{~B}_{10} \mathrm{H}_{12}\right)$ ]. 

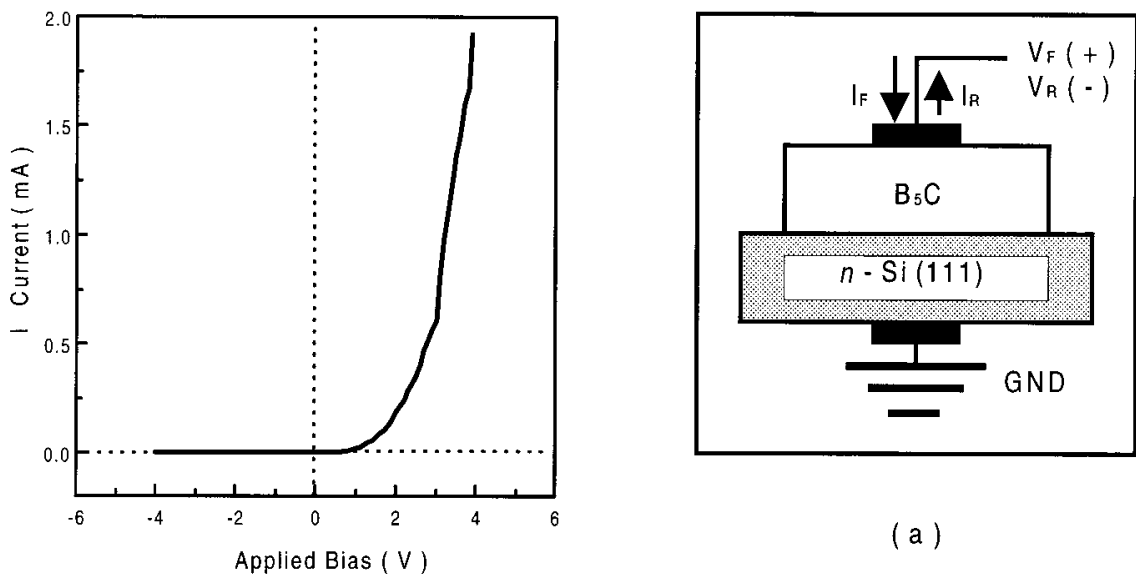

(a)
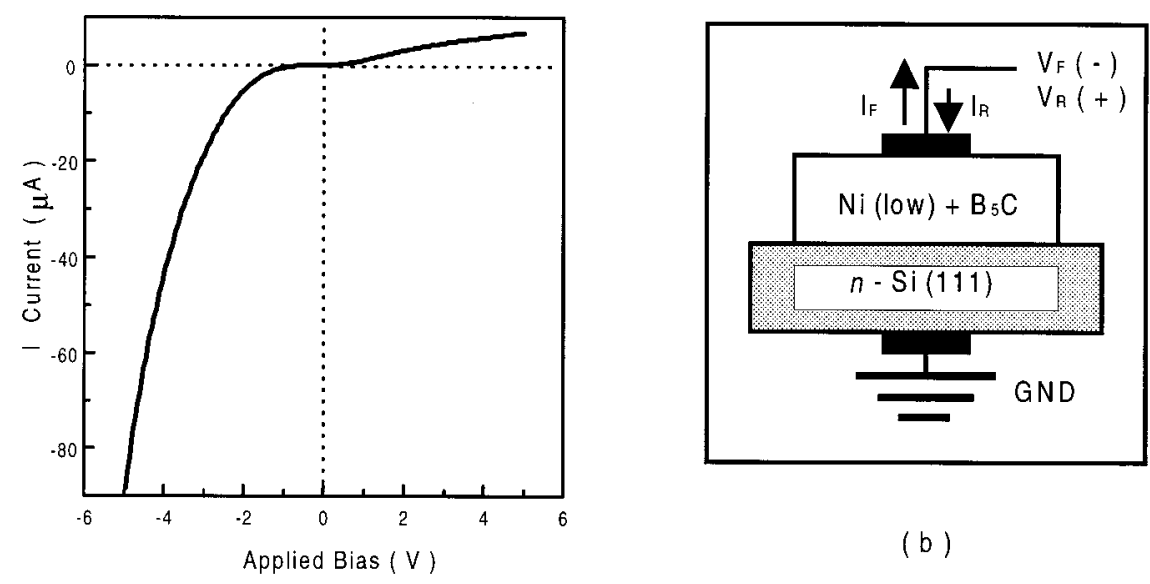

(b)
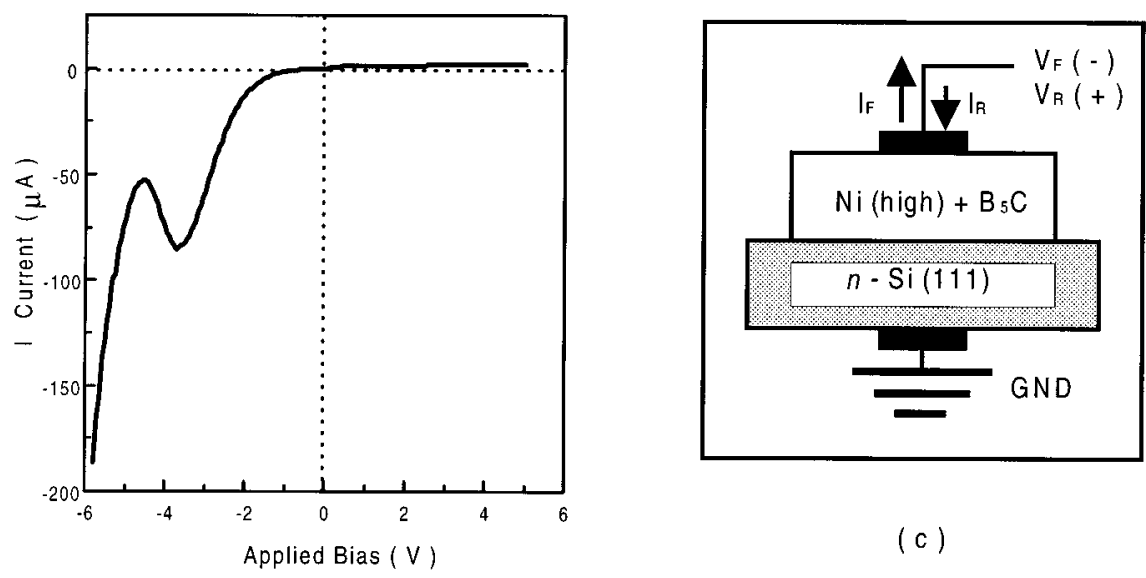

(c)

FIG. 1. The $I-V$ characteristics and the corresponding schematic diagrams of the diodes from (a) $\mathrm{B}_{5} \mathrm{C} / n-\mathrm{Si}(111)$, (b) lightly Ni doped $\mathrm{B}_{5} \mathrm{C}$ on $n$-Si(111), and (c) heavily $\mathrm{Ni}$ doped $\mathrm{B}_{5} \mathrm{C}$ on $n$ - $\mathrm{Si}(111)$. The shift in polarity of the diode demonstrates the relative $n$-type behavior following nickel doping and the characteristic behavior with sufficiently high levels of nickel doping (see the text).

\section{RESULTS AND DISCUSSION}

Typical $\mathrm{B}_{5} \mathrm{C} / n$-type silicon heterojunctions have been routinely formed by this technique. ${ }^{1-4}$ An example of one such diode device is presented in Fig. 1(a). An examination of the $I-V$ curve in Fig. 1(a) shows the excellent diode characteristics of devices built using the technique of PECVD. These devices typically have onsets of $1 \mathrm{eV}$ with very little leakage current (less than $5 \mu \mathrm{A}$ at $25^{\circ} \mathrm{C}$ ). Figure 1(a) also demonstrates the $p$-type character of undoped PECVD boron carbide in this geometry.

The inclusion of $\mathrm{Ni}$ into the boron carbide films with the introduction of nickelocene into the plasma reactor has been verified with Auger electron spectroscopy (AES). The signature of $\mathrm{Ni}$ in the Auger spectra suggest that the Ni uptake is large and that these films are highly doped $\left(\gg 1 \times 10^{21}\right)$. The 

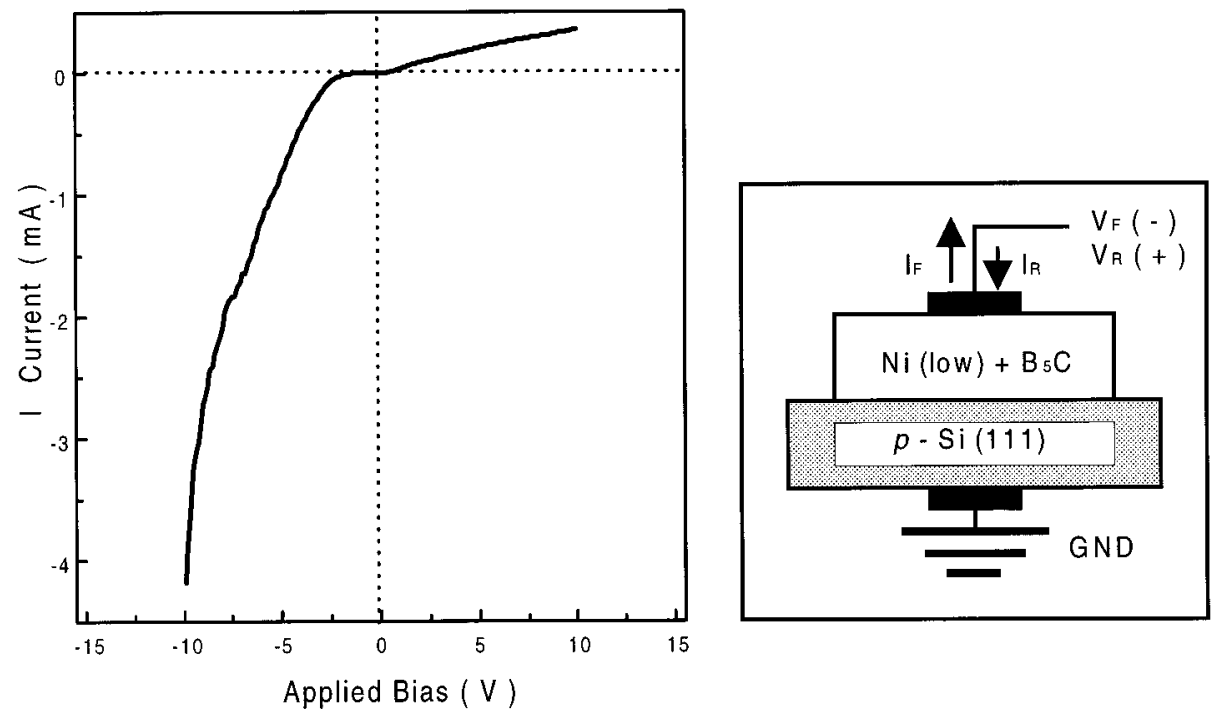

( a )
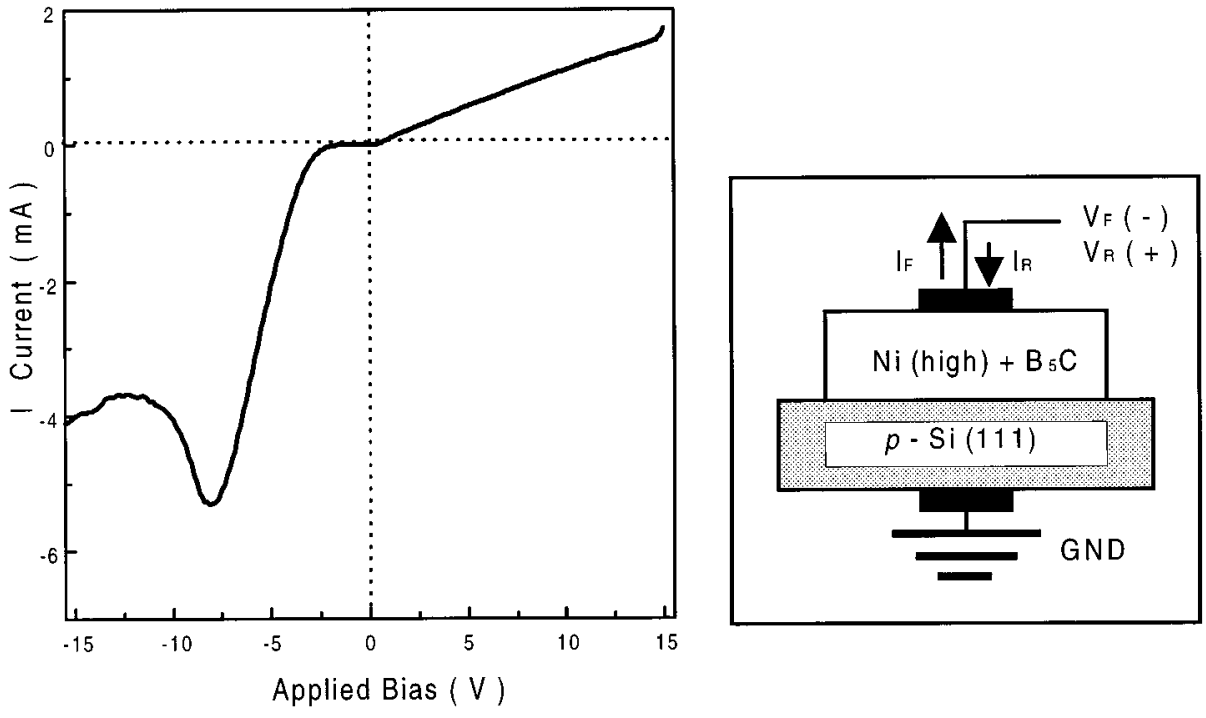

(b)

FIG. 2. The $I-V$ characteristics and corresponding schematic diagrams of the diodes from (a) lightly Ni doped $\mathrm{B}_{5} \mathrm{C}$ on $p$-Si(111) and (b) heavily Ni doped $\mathrm{B}_{5} \mathrm{C}$ on $p-\operatorname{Si}(111)$

$I-V$ curves of two diodes constructed with $\mathrm{Ni}$-doped boron carbide grown on $n$-type $\mathrm{Si}(111)$ are displayed in panels (b) and (c) in Fig. 1. The diode constructed with a "low" level of $\mathrm{Ni}$ doping corresponded to a partial pressure of nickelocene to orthocarborane of $<0.1$ during film growth. The "high" doping corresponded to a relative partial pressure ratio $\approx 9$, respectively.

With the inclusion of $\mathrm{Ni}$, the boron carbide films which are normally $p$-type relative to $n$-type silicon, evolve to an $n$-type material. This is evident from the device characteristics of the diode shown in Fig. 1(b). This results in the formation of rectifying diodes with reverse bias. Thus the nickel doped boron carbide heterojunction diodes appears $n$-type relative to the lightly doped $n$-type silicon substrate. This is consistent with the fabrication of $n-p$ heterojunction diodes on $p$-type silicon, again by including nickelocene with the orthocarborane as an additional source gas, as seen in Fig. 2, for the nickel doped boron carbide.

With the "higher" nickel doping, a negative differential resistance, or a valley in the current, occurs in the effective forward bias direction for diodes formed on both $n$-type silicon and $p$-type silicon substrates, as seen in Figs. 1(c) and 2(b). This behavior is characteristic of a tunnel diode ${ }^{14}$ and is consistent with degenerative doping of a pinned state relative 


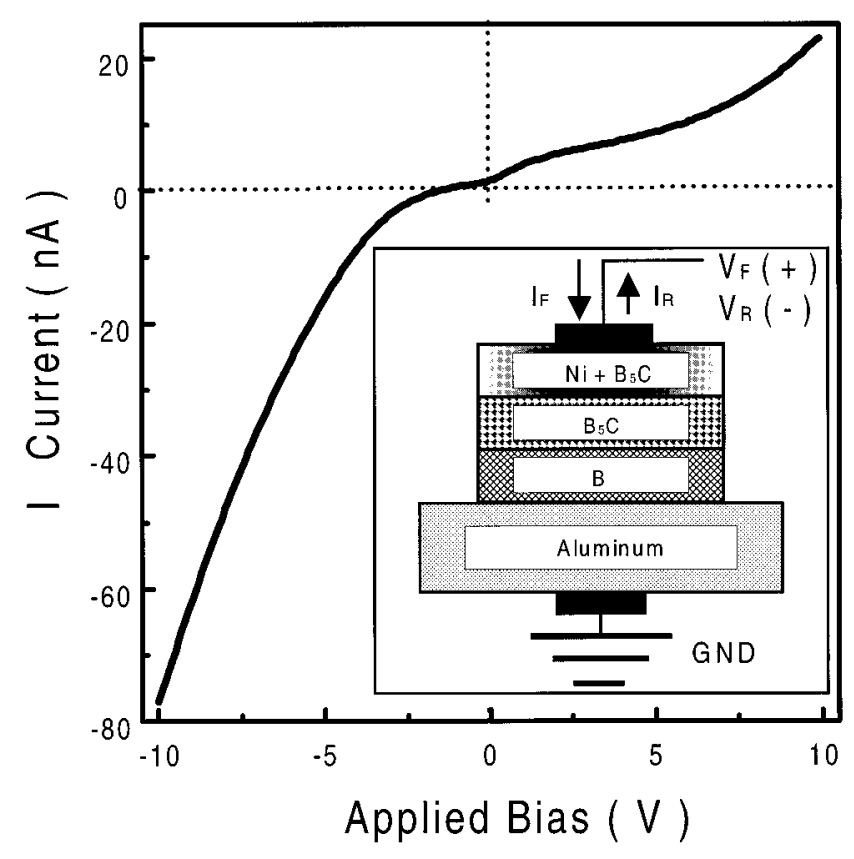

FIG. 3. The $I-V$ characteristics and corresponding schematic diagram of a trilayer diode fabricated from a PECVD $\mathrm{Ni}$ doped $\mathrm{B}_{5} \mathrm{C}$ layer deposited on a PECVD undoped $\mathrm{B}_{5} \mathrm{C}$ layer deposited on a PECVD rhombohedral boron layer placed on an aluminum substrate.

to the conduction band edge. Certainly at the higher doping levels, sufficient nickel from nickelocene is incorporated into the boron carbide during film growth to provide for degenerative doping concentrations.

The hump in the current occurs at a larger bias voltage for the tunnel diodes fabricated on the $p$-type silicon. This is consistent with an $n$-type layer $\left[\mathrm{Ni}_{x} n\left(\mathrm{~B}_{5} \mathrm{C}\right)\right]$ and the formation of heterojunction $n$ - $p$ diodes. In particular, this behavior suggests that the nickel states are pinned to the conduction band edge. States pinned to one band edge have been proposed for boron carbide ${ }^{2}$ and have been identified pinned to conduction band edge. ${ }^{15,16}$ It may be that such states are occupied or filled through nickel doping. Due to the location of the gap states near the conduction band edge, much larger applied voltages should be needed to observe the negative differential resistance for diodes constructed with $p$-type $\mathrm{Si}(111)$, as compared with diodes constructed with $n$-type $\mathrm{Si}(111)$. This is exactly what is observed from the $I-V$ curves of the $n-n$ and $n-p$ diodes in Figs. 1(c) and 2(b), respectively.

PECVD fabricated $\mathrm{B}_{5} \mathrm{C}$-boron heterojunctions can also form diodes on substrates other than silicon, such as aluminum. ${ }^{3}$ Since the construction of diodes through the doping of a layer of $\mathrm{B}_{5} \mathrm{C}$ is now potentially possible, we feel that this advance in the doping of PECVD boron carbide holds the prospect that rhombohedral boron rich semiconductor homojunctions can be formed from this material, without the need of a silicon substrate. A preliminary diode of this type has been fabricated by doping a layer $\mathrm{B}_{5} \mathrm{C}$ with nickel as seen in Fig. 3.

\section{SUMMARY}

In summary, nickelocene can be used to dope PECVD boron carbide. The mildly $p$-type boron carbide, $\mathrm{B}_{5} \mathrm{C}$, relative to $n$-type silicon, is strongly $n$-type following the doping with nickel. With sufficient doping levels, the resulting heterojunction diode acts like a tunnel diode. All evidence suggests that nickel populates states within the gap of this normally highly resistive material. ${ }^{1,2}$

\section{ACKNOWLEDGMENTS}

This work was supported by the AFOSR through Grant No. F49620-94-1-0433, the W. M. Keck Center for Molecular Electronics, and the Center for Materials Research and Analysis. One author (N.B.R.) was supported by the NSFREU program.

${ }^{1}$ S. Lee, J. Mazurowski, G. Ramseyer, and P. A. Dowben, J. Appl. Phys. 72, 4925 (1992).

${ }^{2}$ S. Lee and P. A. Dowben, Appl. Phys. A 58, 223 (1994); S. Lee, T. Ton, D. Zych, and P. A. Dowben, Mater. Res. Soc. Symp. Proc. 283, 483 (1993).

${ }^{3}$ S.-D. Hwang, D. Byun, N. J. Ianno, P. A. Dowben, and H. R. Kim, Appl. Phys. Lett. 68, 1495 (1996).

${ }^{4}$ D. Byun, B. R. Spady, N. J. Ianno, and P. A. Dowben, Nanostruct. Mater. 5, 465 (1995).

${ }^{5}$ D. Byun, S.-d. Hwang, P. A. Dowben, F. K. Perkins, F. Filips, and N. J. Ianno, Appl. Phys. Lett. 64, 1968 (1994).

${ }^{6}$ D. N. McIlroy, Jiandi Zhang, P. A. Dowben, P. Xu, and D. Heskett, Surf. Sci. 328, 47 (1995).

${ }^{7}$ D. N. Mcllroy, J. Zhang, P. A. Dowben, and D. Heskett, Mater. Sci. Eng. (in press).

${ }^{8}$ L. F. Warren and M. F. Hawthorne, J. Am. Chem. Soc. 90, 4823 (1968); 92, 1157 (1970); M. F. Hawthorne, D. C. Young, T. D. Andrews, D. V. Howe, R. L. Pillings, A. D. Pitts, M. Reintjes, L. F. Warren, and P. A. Wegner, ibid. 90, 879 (1968); K. P. Callahan and M. F. Hawthorne, Adv. Organomet. Chem. 14, 145 (1976).

${ }^{9}$ K. Widder, D. Berner, A. Zibold, H. P. Geserich, M. Knupper, M. Kielwein, M. Buchgeister, and J. Fink, Europhys. Lett. 30, 55 (1995); R. J. Cava, Physica C 226, 170 (1994); T. Siegrist, H. W. Zandbergen, R. J. Cava, J. J. Krajewski, and W. F. Peck, Nature 367, 254 (1994); R. J. Cava, Nature 367, 252 (1994); R. Nagarajan, C. Mazumdar, Z. Hossain, S. K. Dhar, K. V. Gopalakrishnan, L. C. Gupta, C. Godart, B. D. Padalia, and R. Vijayaraghavan, Phys. Rev. Lett. 72, 274 (1994).

${ }^{10}$ N. Kobayashi, Y. Kumashiro, P. Revesz, J. Li, and J. W. Mayer, Mater. Res. Soc. Symp. Proc. 162, 595 (1990).

${ }^{11}$ N. Kobayashi, Y. Kumashiro, P. Revesz, J. Li, and J. W. Mayer, Appl. Phys. Lett. 54, 1914 (1989).

${ }^{12}$ Y.-G. Kim, D. Byun, C. Hutchings, P. A. Dowben, H. Hejase, and K. Schroeder, J. Appl. Phys. 70, 6062 (1991); G. T. Stauf and P. A. Dowben, Thin Solid Films 156, L31 (1988); G. T. Stauf, D. C. Driscoll, P. A. Dowben, S. Barfuss, and M. Grade, 153, 421 (1987).

${ }^{13}$ N. M. Boag and P. A. Dowben, Metallized Plastics 4: Fundamental and Applied Aspects, edited by K. L. Mittal (Plenum, New York, 1996); D. Zych, A. Patwa, S. S. Kher, J. T. Spencer, J. Kushneir, A. J. Goodby, N. M. Boag, and P. A. Dowben, J. Appl. Phys. 76, 3684 (1994).

${ }^{14}$ E. O. Kane, J. Appl. Phys. 32, 83 (1961); E. O. Kane, Phys. Chem. Solids 2, 181 (1960); A. G. Chynoweth, W. L. Feldmann, and R. A. Logan, Phys. Rev. 121, 684 (1961); R. A. Logan and A. G. Chynoweth, ibid. 131, 89 (1963); R. S. Claassen, J. Appl. Phys. 32, 2372 (1961); A. S. Epstein and J. F. Caldwell, ibid. 35, 3050 (1964); D. Meyerhofer, G. A. Brown, and H. S. Sommers, Jr., Phys. Rev. 126, 1329 (1962); R. M. Minton and R. Glicksman, Solid-State Electron. 7, 491 (1964); J. Karlovsky, ibid. 10, 1109 (1967).

${ }^{15}$ H. Werheit, U. Kuhlmann, M. Laux, and T. Lundstrøm, Phys. Status Solidi B 179, 489 (1993).

${ }^{16}$ H. Werheit, M. Laux, and U. Kuhlmann, Phys. Status Solidi B 176, 415 (1993). 